\title{
Second Language Vocabulary Learning from Viewing Video in an EFL Classroom
}

\author{
Rattana Yawiloeng $^{1}$ \\ ${ }^{1}$ School of Liberal Arts, University of Phayao, Phayao, Thailand \\ Correspondence: Rattana Yawiloeng, School of Liberal Arts, University of Phayao, Phayao, Thailand, 56000
}

Received: May 26, 2020

Accepted: June 18, 2020

Online Published: June 23, 2020

doi: 10.5539/elt.v13n7p76

URL: https://doi.org/10.5539/elt.v13n7p76

\begin{abstract}
This study examines the effects of an English vocabulary video on second language vocabulary learning by English as a foreign language (EFL) learners. The conceptual framework is underpinned by Mayer's (2005) Cognitive Theory of Multimedia Learning. The participants were 25 undergraduate students studying at a Thai university. To collect data, five types of research instruments were utilized including a survey of English vocabulary knowledge, pre-test, post-test, the English vocabulary video, and a questionnaire. The findings of this study revealed an increase in the post-test scores after the Thai EFL learners engaged in learning second language (L2) vocabulary using an English vocabulary video. Moreover, the findings also uncovered that the EFL learners gained L2 vocabulary knowledge after viewing the video containing first language (L1) and L2 captions, images, and L2 audios which are relevant to the target words. Furthermore, the results revealed that the EFL students preferred learning L2 vocabulary via video containing both L1 and L2 captions, interesting and related images, and the proper volume of audios. Therefore, the significant findings of this study lead to theoretical and pedagogical implications regarding the significant role of multimedia learning in terms of the links between visual and auditory information.
\end{abstract}

Keywords: L2 vocabulary learning, EFL learners, multimedia learning, video modalities

\section{Introduction}

In recent years, researchers have become increasingly interested in research on learning vocabulary. This is because it is viewed as a crucial pathway of the first language (L1) and second language (L2) proficiency (Azman \& Mei, 2015; Nation, 2001; Vasu \& Dhanavel, 2015). In the same way, learning vocabulary is viewed as a fundamental stage of language learning (Alhamani, 2014; Nation, 2001). Particularly in L2 learning, L2 vocabulary development can enhance other language skills since the elemental units of language are lexical items which are necessary for L2 learners to develop their listening, speaking, reading, and writing skills (Alhamami, 2014). From this view, understanding L2 vocabulary can assist learners to gain more understanding of the target language and more opportunities to engage in an early stage of L2 learning development. In accordance with this view of L2 vocabulary learning, Lin (2010) posits that limited vocabulary knowledge can cause L2 learners to be less successful in reaching an advanced level of listening, speaking, reading, and writing. Several studies have reported that multimedia can be used to assist learners to gain vocabulary knowledge through audio and visual channels (i.e., Kanellopoulou, Kermanidis, \& Giannakoulopoulos, 2019; Rahimi \& Allahyari, 2019; Ramezanali \& Faez, 2019). According to the Cognitive Theory of Multimedia Learning (CTML), multimedia learning is based on the view that learning is promoted when students generate "meaningful connections between the verbal and visual mental representations" (Xu, 2010, p. 312). Through an exploration of the essential role of multimedia on L2 vocabulary learning, this study aimed at investigating the effects of multimedia modalities on L2 vocabulary learning.

\subsection{Difficulties in Second Language Vocabulary Learning}

It is commonly viewed that inadequate knowledge of L2 vocabulary can obstruct learning English as a second language (ESL) and learning English as a foreign language (EFL). Vasu and Dhanavel (2015) mentioned that ESL learners experience obstacles to use language effectively because of inadequate vocabulary knowledge as well as relevant word knowledge. Consequently this problem hinders their efficient language use. Furthermore, another potential difficulty with learning unfamiliar vocabulary is a lack of sufficient information about vocabularies such as textual definitions and still images (Lin \& Tseng, 2012). Jung and Lee (2013) found out 
that EFL learners were unaware of how to predict word meanings from video clips which may cause them to feel pressured at the beginning stage of L2 vocabulary learning. For EFL learners, learning L2 vocabulary appears more difficult than learning their L1. As a result, the EFL learners experience less successful L2 learning. To overcome the difficulty of unfamiliar L2 vocabulary learning, researchers have suggested using multimedia in language classrooms such as videos to help learners to locate textual definitions and pictorial aids to better comprehend the meanings of new words (Lin \& Tseng, 2012).

\subsection{Obstacles of Thai EFL Learners in Second Language Vocabulary Learning}

Previous research on L2 vocabulary learning in the Thai EFL context has reported that Thai students experience difficulties in learning English vocabulary (Boonkongsaen \& Intaraprasert, 2014; Saengpakdeejit, 2014). EFL students typically learn L2 vocabulary by memorizing unfamiliar vocabulary after learning and searching for the definitions of new words through the use of a bilingual dictionary. As a result, EFL learners find it hard to achieve successful L2 vocabulary learning (Boonkongsaen \& Intaraprasert, 2014). At this point, learning vocabulary using a memorizing strategy may cause problems when learners have short-term memory or limited working memory capacity in L2 vocabulary. This means that EFL learners possibly forget or lose information that they have learned due to insufficient working memory (Wang, 2012). Moreover, Thai EFL learners discovered that their key learning language problem to resolve is limited vocabulary knowledge (Saengpakdeejit, 2014). Lastly, due to EFL learners' limited L2 vocabulary knowledge, they find it difficult to guess the meaning of unfamiliar L2 vocabulary without sufficient contextual clues. Thus, to overcome EFL students' obstacles in L2 vocabulary learning, it is worth studying the effects of the use of videos for L2 vocabulary learning.

Recent studies suggest that technology can support learners to learn L2 vocabulary. In the age of Information Technology (IT), some researchers point to the important roles of technology-assisted vocabulary learning and computer-assisted language learning (CALL). This is in terms of the link to L2 vocabulary learning as well as L2 vocabulary acquisition (e.g., Ko \& Goranson, 2014; Liu, Lan, \& Jenkins, 2014; Maftoon, Hamidi, \& Sarem, 2012; Tabar \& Khodareza, 2012; Zarei \& Gilanian, 2013). Opportunities to engage in a technology-assisted vocabulary learning program can promote students to acquire word meanings effectively and efficiently because they engage in various exercises, repeated questions in different forms, and have access to a convenient online system (Ko \& Goranson, 2014). Furthermore, Maftoon et al. (2012) emphasized that L2 learners can learn a language independently at any time and in any place via classrooms applying computer technologies, software, and learning programs. Thus, in order to support learners to learn unfamiliar vocabulary, providing them with more opportunities to encounter the target language with technology and multimedia may support L2 vocabulary acquisition.

In this digital era, previous studies have investigated the effects of multimedia in promoting L2 learners' vocabulary knowledge and facilitating L2 learning development. Shao (2012) explored the use of multimedia software to assist EFL Chinese learners in L2 vocabulary acquisition. They also explored the EFL students' interests in multimedia software and their attitudes towards the multimedia application. The results of their study revealed that the EFL learners reflected highly positive attitudes towards the application of the multimedia software. In line with Shao's (2012) study, the results revealed that vocabulary acquisition can derive from the application of effective multimedia. Similarly, Tabar and Khodareza (2012) investigated vocabulary learning using multimedia by Iranian learners at the pre-intermediate and intermediate levels. In this study, the multimedia software, Vocaboly, was used combined with teacher-led instruction. Tabar and Khodareza (2012) found that the multimedia software supported the EFL learners to learn and retain significantly more vocabulary compared to participating in teacher-led groups. In short, the findings of these previous studies on L2 vocabulary learning showed the links between using multimedia materials and L2 vocabulary learning.

However, previous studies on L2 vocabulary learning have neglected to examine how multimedia modalities can enhance language learner vocabulary learning and how the learners perceive L2 learning via the use of multimedia in an EFL context. Previous studies have revealed a positive effect of using multimedia such as videos on L2 vocabulary learning; however, few studies have focused on the effects of video modalities; namely, audios, images, and captions on L2 vocabulary learning. Moreover, there have been fewer studies of learners' attitudes towards the use of video in EFL classrooms and their attitudes towards each modality in videos on their L2 vocabulary learning. Over recent decades, videos have been used in English language classrooms to help learners to understand English vocabulary. However, there is little research in Thailand to examine the impact of video use on Thai EFL learners' L2 vocabulary learning. This is particularly the case for English vocabulary in Information and Technology which is crucial for EFL learners in this digital age. Therefore, this current study investigated the effects of L2 vocabulary video use on EFL learner English vocabulary learning. It also explored the EFL learners' attitudes towards the use of vocabulary videos in the EFL classroom. 


\section{Literature Review}

\subsection{Theoretical Background of Vocabulary Learning through Multimedia}

Cognitive Theory of Multimedia Learning (CTML) is a theoretical framework for research on L2 vocabulary learning through multimedia. According to Mayer (2005; as cited in Lin \& Tseng, 2012, p. 347), the CTML categorizes all input information into two types, verbal and non-verbal. It maintains the brain perceives, comprehends, subsumes, and merges new information into the existing system. When the learning content is well controlled (intrinsic cognitive load) and the presentation is well designed (extraneous cognitive load), effective learning is likely to take place (germane cognitive load) (Lin \& Tseng, 2012, p. 347). In this theory, the dual channel assumption suggests that humans have two separate information processing channels: auditory or verbal and visual or pictorial. The verbal channel receives information (e.g., spoken or written words, narrations, and sounds) via the ear and eyes, and the visual channel processes the information (e.g., pictures, graphs, video animation clips, and on-screen texts) via the eyes (Mayer, 2014; as cited in Ramezanali \& Faez, 2019, p. 106). In sum, CTML theory has implications for research on L2 vocabulary learning that multimedia can be used to promote such learning by connecting pictorial and audio information to enhance vocabulary knowledge of learners.

\subsection{Second Language Vocabulary Learning}

Research on L2 vocabulary learning has found that vocabulary learning involves both intentional and incidental learning (Nation, 2001). Based on Nation (2001; as cited in Rasouli \& Jafari, 2016, p. 42), form, collocation, and word classes should be taught/ learned incidentally, whereas aspects of meaning, register, and other constraints are better learned through direct explicit instruction. Thus, many L2 researchers focus on incidental learning in L2 vocabulary research in the hope that the concept will lead to the teaching of vocabulary (e.g., Arndt \& Woore, 2018; Ramos, 2015; Sok, 2014).

Vocabulary knowledge plays an important role in L2 vocabulary learning. Nation (2008) identified three ways to learn a new word: meaning (form and meaning, concept and referents, associations), form (spoken form, written form, word parts), and use (grammatical functions, collocation, constraints on use). The link between understanding the word form and meaning and acquiring word knowledge occurs because the learner repeatedly engages with and uses the word to gradually develop new knowledge (Schmitt, 1995). Agreeing with Nation (2008), Alhamami (2014) also highlighted the important role of the L1 translation along with the use of pictures to provide meaningful definitions of the target words. Therefore, to support L2 vocabulary learning, it is important to identify effective ways to enhance EFL learners' L2 vocabulary learning development.

\subsection{Video as Multimedia Tool to Enhance L2 Vocabulary Learning}

Video can assist in representing the content, expanding understanding, and improving vocabulary and grammar learning. As such, it is often favored as a multimedia learning tool (Wang, 2012). In recent years, researchers have become increasingly interested in the use of video due to its benefits to L2 vocabulary learning (e.g., Lin, 2011; Zarei \& Gilanian, 2013). Lin's (2011) study found a link between the development of L2 understanding capacity and vocabulary learning using videos and applying CALL programs. The author suggested the use of easy video texts to support learners in achieving vocabulary acquisition. Lin (2010) also highlighted the benefits of video-based CALL programs where multimedia makes it possible for students to learn vocabulary aided by sounds and pictures. In addition, Azman and Mai (2015) have claimed that glosses in multimedia facilitate vocabulary learning among L2 learners. The researchers indicated that multisensory materials, words, audios, images, and animation can be utilized through the use of text and graphics to help learners to engage in meaningful contexts to aid comprehension (Azman \& Mai, 2015). It is therefore helpful for vocabulary pedagogy to use innovations for learning vocabulary in this modern era because technological materials feature in the learners' everyday lives (Alhammami, 2014).

Previous studies have shown the positive links between using videos and vocabulary learning (Durbahn, 2019; Kabooha \& Elyas, 2018; Wang, 2012). Kabooha and Elyas (2018) conducted an experimental study of the effects of YouTube in multimedia instruction for vocabulary learning by collecting data from both EFL students and teachers. After conducting pre-tests, post-tests, and questionnaires, the finding uncovered that $100 \mathrm{EFL}$ students improved their L2 vocabulary comprehension by utilizing YouTube technology. Importantly, Kabooha and Elyas (2018) asserted that the use of YouTube in teaching and learning can be effective for target vocabulary recognition, comprehension, and retention (Kabooha \& Elyas, 2018). Moreover, both EFL students and teachers reported positive perceptions of YouTube in their English lessons, leading to vocabulary acquisition by the students. These significant results from Kabooha and Elyas (2018) shed the light on further research recommendations that YouTube videos should be chosen according to the learners' proficiency levels, cultural 
issues, and the lesson goals. Recently, the use of multimedia resources was explored in a study by Durbahn (2019). The author found that L2 learners gain incidental vocabulary acquisition after learning L2 vocabulary via documentary video viewing. The research collected quantitative data from 34 learners (16 EFL and $18 \mathrm{ESL}$ learners) by conducting a pre-test/ post-test around watching two documentaries. Durbahn's (2019) findings indicated that vocabulary acquisition was linked to the video captions the learners viewed. According to Durbahn (2019), learners who viewed video captions gained an additional $8 \%$ of vocabulary knowledge compared to viewing uncaptioned videos. In addition, the learners gained benefits from the captioned video in terms of meaning recognition, form recall, and the spelling of new vocabulary. Durbahn (2019) suggested that the role of imagery in the vocabulary incidental learning process should be emphasized in future research. As mentioned above, there are advantages to using videos in language classrooms and it is therefore suggested that they are used by language teachers to enhance effective L2 vocabulary acquisition.

\subsection{The Links between Visual and Auditory Modalities and L2 Vocabulary Learning}

The use of visual and auditory modalities is viewed as an effective way to enhance L2 vocabulary learning. Computerized media and multimedia environment are regarded particularly beneficial for learning foreign language vocabulary in SLA contexts (Shao, 2012). Learning vocabulary through multimedia that includes pictures, sounds, written texts, and videos can support the transfer of messages in unique ways (Shao, 2012, p. 203). The reasons why multimedia can help learners to overcome L2 vocabulary learning difficulties is as a result of the link between memory and images and because multimedia supports more opportunities to encounter the L2 (Shao, 2012). Input from visual and auditory modalities is also used in language pedagogy because multiple modalities can promote better recall in language learning (Sydorenko, 2010). Moreover, Mohsen and Balakumar's (2011) study revealed the positive effects of multimedia glosses in CALL. In particular "multimedia glosses, either in reading comprehension activities or in listening comprehension activities, and their impact on L2 vocabulary acquisition have been addressed in CALL studies" (p. 135). According to Khazaie and Ketabi (2011), multimedia technology provides benefits to L2 learners because "reliable, high quality audio and video delivery to user-friendly mobile devices can provide valuable and enjoyable language input to learners" (p. 174). To conclude, images, audios, and messages contained in multimedia materials such as videos can enhance L2 vocabulary learning.

\section{Method}

\subsection{EFL Classroom Context}

This study was conducted in an EFL classroom at a Thai university. Fifty-Five undergraduate students were registered in a Practical Reading and Writing course for 16 weeks. These non-English major students studied English once a week for three hours. In the classroom context, the EFL students communicated to the teacher and to each other using both Thai and English.

\subsection{Participants}

Purposive sampling was used to recruit 25 participants from 55 undergraduate students enrolled in the Practical Reading and Writing course. The EFL students participated in this study during the first few weeks of the semester. Studying at the university, the participants attended an English class for three hours per week. The participants' L1 is Thai and their L2 is English.

\subsection{Research Design}

The quasi-experimental pre-test-post-test design was deployed to study the effects of video use on English vocabulary learning. This study compared the pre-test and post-test scores before and after viewing the video of unfamiliar English words.

\subsection{English Vocabulary Video}

The instruments used in this study included a word list, vocabulary pre-test, vocabulary post-test, the video, and the semi-structured interviews. (1) Word Lists of basic computer vocabulary were selected from the Computer Word List at http://www.enchantedlearning.com. The list was used to survey computer-related English words unfamiliar to the EFL students. (2) The English Vocabulary Background Survey included a multiple-choice vocabulary test. It was administered to assess the participants' knowledge of computer words in order to identify unfamiliar words. The purpose of this survey was to identify the unfamiliar computer vocabulary for the participant. Twenty-five unfamiliar computer words were selected to include in the English vocabulary video. (3) The pre-test and post-test were designed based on the 25 unfamiliar computer words from the survey questionnaire with four multiple choices. The tests aimed to evaluate the participants' knowledge of the unfamiliar English computer words before and after using the video to learn the L2 vocabulary. To ensure the 
reliability of the pre-test and post-test, the tests were piloted on 10 second-year undergraduate students similar to the participants. To ensure reliability, Kudar-Richardson's Reliability Coefficient was coined and showed a 0.70 score. (4) The English Vocabulary Video contained 25 unfamiliar computer-related words derived from the survey designed by the researcher. The video consisted of L2 vocabulary, images, sound, English (L2) meanings, Thai (L1) meanings, English sample sentences, and the sources of the meanings and photos. The video was 2.40 minutes duration and included 25 unfamiliar English computer words arranged alphabetically; namely, "Bookmark, Broadband, Browser, Cookie, Dashboard, Domain, Drag, Firewall, Freeware, Hyperlink, Malware, Modem, Monitor, Phishing, Plug-ins, Privacy, Restore, Screen, Scroll, Shareware, Snapshot, software, spyware, Wiki, and Zip". (5) The semi-structured interviews were conducted to gain insight data of the EFL students' attitudes towards L2 vocabulary videos and the difficulties around using videos for L2 vocabulary learning.

\subsection{Procedures}

This study was conducted during the English classes. The researcher first contacted the course director of the Practical Reading and Writing course to acquire permission to conduct the study and to briefly describe the research plan. After obtaining permission from the course director, the researcher sought permission from the university to access the classroom for data collection. The researcher then met with the participants to provide a brief of the research plan. To collect data, the research procedures were conducted as follows:

\subsubsection{Surveying Unfamiliar English Vocabulary}

The survey test of English vocabulary knowledge comprising 33 items was administered to the students to identify only unfamiliar words. The duration of the survey was 30 minutes. After conducting the test, 25 computer-related words unfamiliar to the EFL participants in terms of form and meaning were chosen.

\subsubsection{Administering the Pre-test}

The pre-test of the 25 computer words was given to the participants to complete within 30 minutes.

\subsubsection{Designing the English Vocabulary Video}

The researcher designed the English vocabulary video following a review of the theory of L2 vocabulary acquisition using multimedia. This video consisted of 25 unfamiliar computer-related words. To enhance L2 vocabulary acquisition, the video's components included English vocabulary, images, audios, English meanings, Thai meanings, sentence samples, and the sources of all information.

\subsubsection{Viewing the Video}

The participants were asked to watch the English vocabulary video (2.40 minutes duration). The viewing session was 60 minutes duration during which time the participants could watch the video as many times as they wanted to. To access the video, the researcher created a Facebook closed group and asked all participants to join. The researcher then posted the video to the Facebook group so that all participants could access it through computers in the classroom.

\subsubsection{Administering the Post-test}

The post-test was given to the participants after they watched the English Vocabulary Video for 60 minutes. To collect qualitative data, the researcher administered opened-ended questionnaires and conducted semi-structured interviews to elicit the EFL students' attitudes towards the use of video to enhance L2 vocabulary acquisition.

\section{Results}

\subsection{Effects of the English Vocabulary Video on L2 Vocabulary Learning}

Table 1 below shows the pre-test and post-test scores for vocabulary knowledge of 25 unfamiliar English words gained by the Thai EFL learners. The 25 computer-related vocabulary in English included "Bookmark, Broadband, Browser, Cookie, Dashboard, Domain, Drag, Firewall, Freeware, Hyperlink, Malware, Modem, Monitor, Phishing, Plug-ins, Privacy, Restore, Screen, Scroll, Shareware, Snapshot, software, spyware, Wiki, and Zip".

Table 1. Pre-test and post-test scores of the Thai EFL learners

\begin{tabular}{llllll}
\hline & Number & Pre-test & Post-Test & Gain & Sig. \\
\hline Mean & 25 & 12.56 & 16.92 & 4.60 & 0.00 \\
S.D. & 25 & 4.292 & 3.872 & 2.380 & 0.00 \\
\hline
\end{tabular}


As shown in Table 1, the Thai EFL students' post-test scores for their English vocabulary knowledge were higher than their pre-test scores after viewing the English Vocabulary video. The means and standard deviations (S.D.) of the EFL students' pre-test scores were 12.56 and 4.292. Unlikely, these EFL students' means and standard deviations of post-test scores were 16.92 and 3.872, respectively. This indicates that the EFL students achieved higher scores after viewing the vocabulary video. A comparison of the pre-test and post-test mean scores shows the results of the tests were highly significant $(0.00)$. The means and standard deviation of the gain scores were 4.60 and 2.380, respectively. As hypothesized, the post-test scores were expected to be higher than the pre-test scores. The results of this study revealed that there is a highly significant increase in the post-test scores compared to the pre-test scores on the EFL students' English vocabulary test. In short, viewing an English vocabulary video appears to enhance the Thai EFL students' abilities to acquire L2 vocabulary knowledge as evidenced by their higher post-test scores.

\subsection{EFL Learners' Attitudes towards the English Vocabulary Video}

Table 2 further shows the quantitative results of the 25 EFL students' attitudes towards learning vocabulary using an English Vocabulary video. After viewing the video, the Thai EFL students were asked to rate their attitudes towards the features of the video in terms of its introduction, content, language use, length, video component, and interaction design.

Table 2. EFL learners' attitudes towards the English vocabulary video

\begin{tabular}{|c|c|c|}
\hline Attitudes towards the features of the vocabulary video & $\mathrm{M}$ & S.D. \\
\hline 1. Introduction (interesting and necessary information) & 2.72 & 0.614 \\
\hline $\begin{array}{l}\text { 2. Content (structure, accuracy, clear aims, suitable for students' proficiency } \\
\text { levels) }\end{array}$ & 3.20 & 0.645 \\
\hline 3. Language use (correct and suitable for students' proficiency levels) & 3.20 & 0.707 \\
\hline $\begin{array}{l}\text { 4. Lesson design (relevant content, creative, considerate of individual } \\
\text { differences) }\end{array}$ & 3.36 & 0.638 \\
\hline 5. A suitable length, interesting presentation strategies & 2.76 & 0.779 \\
\hline $\begin{array}{l}\text { 6. Video components (size and color are easy to read and suitable for students; } \\
\text { beautiful and suitable graphics) }\end{array}$ & 2.72 & 0.980 \\
\hline 7. Interaction design (easy to navigate and to move forward or backward) & 3.24 & 0.723 \\
\hline
\end{tabular}

Table 2 shows the attitudes of 25 EFL learners towards each feature of the English vocabulary video, ranging from 1 to 4 (strongly disagree, disagree, agree, strongly agree). Overall, the Thai EFL students agreed with the use of an English vocabulary video. This suggests that the Thai undergraduate students regarded the English Language Video as effective in L2 vocabulary learning. In the first rank, the Thai EFL students evaluated the 'Lesson design' of the English Language Video in terms of relevant content, creativity, and an awareness of individual differences. The mean score (3.36) and standard deviation (0.638) outcomes indicate that the students agreed with the lesson design of the English vocabulary video. In the second rank, the students evaluated the 'Interaction design of video' in terms of easiness to navigate and to forward or backward. The mean score (3.24) and standard deviation $(0.779)$ results indicate that the students agreed with the interaction design of the video. The students also evaluated the 'Introduction' to the video in term of being interesting and including necessary information. The mean score (2.72) and standard deviation (0.614) outcomes indicate that the EFL students considered the introduction of the video to be interesting and that it contained the necessary information related with the target language. To conclude, the Thai EFL students agreed that all features of the English vocabulary video were good, with the lesson design achieving the highest ranking and the introduction achieving the lowest ranking.

\subsection{Qualitative Results: The EFL Learners' Attitudes towards Modality of the English Vocabulary Video}

Table 3 shows the analysis results for the qualitative data collected via semi-structure interviews with the EFL students to elicit their attitudes towards the modalities of the video. The EFL students' responses suggested a favorable attitude towards the modalities of the video; namely, Thai (L1) and English (L2) captions, vocabulary images, and vocabulary audios in English pronounced by English native speakers. 
Table 3. EFL learners' attitudes towards the modalities of the English vocabulary video

\begin{tabular}{|c|c|}
\hline $\begin{array}{l}\text { Modalities of the } \\
\text { L2 vocabulary video }\end{array}$ & Statements \\
\hline Thai (L1) and English (L2) captions & $\begin{array}{l}\text { - } \quad \text { Thai captions can help to understand vocabulary meaning } \\
\text { - } \quad \text { Both Thai and English captions can help understand }\end{array}$ \\
\hline Vocabulary images & $\begin{array}{l}\text { - } \quad \text { Some images were interesting } \\
\text { - } \quad \text { Images in the video can support better understanding }\end{array}$ \\
\hline L2 vocabulary audios & - Audio can arouse students' interest \\
\hline
\end{tabular}

According to Table 3, the EFL students viewed the captions in the English vocabulary video both in Thai (L1) and English (L2) as helpful to their easier understanding of English vocabulary meanings. In addition, vocabulary images presented in the video were viewed by the participants as interesting and helpful for understanding the English vocabulary. Lastly, the EFL students mentioned that English vocabulary audios embedded into the video aroused their interest in L2 vocabulary learning. In brief, the EFL students indicated positive attitudes towards the English vocabulary video captions, images, and audios. The possible explanation for this result is that the EFL students could understand the unfamiliar English words through the images representing the words as well as the English audios to support their understanding of the word meaning.

Table 4. Difficulties around L2 vocabulary learning from using the video

Sample comments on the difficulties of L2 vocabulary learning using the vocabulary video

Difficulties with the Thai (L1) and English (L2) captions

- Captions presented too quickly meant that the learners could not catch up with the vocabulary meanings.

- Long Thai (L1) captions resulted in poorer understanding and reduced interest in vocabulary meaning.

- Captions were small and uninteresting.

- Thai captions were too formal and had to be interpret again.

Difficulties with the vocabulary images

- Some images were irrelevant in relation to the meaning of the vocabulary.

- Some images were not interesting and led to difficulties in understanding the words' meaning.

- Images were often presented too quickly causing the learners to miss key points.

Difficulties with the L2 audios and background music

- The background music was too loud which was annoying, and which diminished learner attention

According to Table 4, the Thai EFL students indicated that the difficulties they encountered while learning English vocabulary via the video ranged from problems understanding the Thai (L1) and English (L2) captions, vocabulary images, and audios in English, respectively. From the interview data, the captions used to describe the English vocabulary in the video were considered by most participants to create difficulties for the EFL students due to being presented too quickly or being too long or too small. This led the EFL students to regard them as uninteresting and difficult to understand their meaning. Importantly, although the Thai (L1) captions were useful for explaining English vocabulary, the Thai EFL students emphasized that Thai captions which were too long and too formal also caused them difficulties in understanding some English words. The overly formal Thai and English captions were time consuming to interpret for their meaning in English. Furthermore, the irrelevant, uninteresting, and fast images presented in the English vocabulary video were viewed as obstacles to L2 vocabulary learning. Moreover, the music background audios that were too loud according to the listeners could be annoying and reduced their level of attention. In sum, inappropriate presentations of the captions, images, and audios may obstruct English vocabulary learning by EFL students.

\section{Discussion}

This study examined the effects of using an English vocabulary video for L2 vocabulary learning by the EFL learners. Mayer's (2005) CTML was applied as a theoretical framework. 


\subsection{Effects of Multimedia on L2 Vocabulary Learning}

The findings from both the quantitative data and qualitative data analysis in this present study indicate that the use of an English vocabulary video is linked to L2 vocabulary gains. Based on Mayer (2014), the video is viewed as a sample of "dynamic pictorial materials (one form of multimedia) such as illustrations, graphs, diagrams, maps, animations, or videos" (p. 2). According to the findings of Ramezanali and Faez (2019), L2 word definitions can by acquired through the use of video animation rather than learning textual definitions only. When comparing two L2 vocabulary learning modes, L2 learners indicated a preference for L2 definitions to be presented along with the video animation mode. L2 definitions presented along with audio glossing was their second choice (Ramezanali \& Faez, 2019). The researchers suggested that the preference for video animations may be due to the L2 learners limited working memories, thereby leading them to depend on the images presented in the video animation to understand the meaning of the words (Ramezanali \& Faez, 2019).

The results of this study also confirm that images or visual representations in the video play an important role in learning unfamiliar L2 vocabulary. According to the Thai EFL students who participated in the present study, the images in the video were interesting and promoted understanding of L2 vocabulary meaning. This is consistent with the findings reported by Khazaie and Ketabi (2011) in their study of the potential of mobile phones to contribute to vocabulary learning. This study revealed that "delivery of learning materials with pictorial annotation to learners with both high-visual but low-verbal ability results in better vocabulary learning" (Khazaie \& Ketabi, 2011, p. 178). Based on their findings, Khazaie and Ketabi (2011) recommended the application of mobile applications in L2 vocabulary pedagogy while also forewarning however the limitations around using mobile devices as a replacement for common classroom instruction.

\subsection{Connections between Image and Audio Information in the Video}

Based on the pre-test, post-test and semi-structured interview data analysis results, the English vocabulary video containing captions, images, and audio information was effective in enhancing the EFL students' L2 vocabulary learning. This result may be considered as a promising aspect of CTML that provides clear understanding of how multimedia presentations of information can be stored in working memory. Here, the knowledge is constructed from the sounds and visual images of the words, with the new knowledge in the working memory integrated with the learner's prior knowledge in the long-term memory. As such, multimedia learning can take place (Mayer, 2005, pp. 37-38). The finding of this study is also consistent with the finding reported by Ramezanali and Faez (2019) that dual glossing modes (L2 definition, aural, and video animation) are effective for vocabulary learning. This study also found that presenting L2 definitions via video animation mode appeared to be more effective than presenting the definition via audio glossing mode only (Ramezanali \& Faez, 2019). Ramezanali and Faez (2019) claim video animation can promote vocabulary learning; that is, videos stimulate the curiosity of learners to follow the clips and to develop form-meaning relationships between a word and its meaning. In addition, Lin and Tseng (2012) claim that videos have the features to represent form-meaning connections and to provide a gestalt, dynamic stimuli that are easy to remember, helping to build more effective mental images of the target words (p. 351). Similarly, Cepon's findings (2013) show that some EFL students think that it is easier to memorize meaningful phrases or combined words. Moreover, reading English subtitles appears to be beneficial when learning the meanings of unfamiliar words (Cepon, 2013). Importantly, half the EFL learners in Cepon's (2013) study indicated that viewing video could reduce anxiety and stress while learning in the EFL classrooms. Therefore, the connections between the audio and image elements in videos play an important role in learner L2 vocabulary knowledge development. This knowledge can be also integrated with learner's relevant prior knowledge of the words, thereby supporting the acquisition of L2 vocabulary.

\subsection{L1 and L2 Captions for Enhancing L2 Vocabulary Learning}

Based on the qualitative data analysis results, the finding shows that the use of relevant captions in Thai (L1) and English (L2) can enhance the English vocabulary knowledge of EFL learners. This finding is supported by the CTML's perspective of processing of on-screen text or printed text involving the cognitive process mediating the selection of relevant words (Mayer, 2005). Regarding the cognitive processes in CTML, Mayer (2005) describes how the "learner pays attention to relevant words in a multimedia message to create sounds in working memory" (Mayer, 2005, p. 41). For the processing of printed words, Mayer (2005) explains that the printed text in multimedia messages presents difficulties around information processing in a dual-channel system.

The finding in this study that L1 and L2 captions can assist L2 vocabulary confirms Rodgers' (2013) finding that captions can promote vocabulary comprehension at the lexical level by learners with limited L2 schema. However, ineffective captions such as those that are: presented quickly, lengthy, tiny, and official may provide less support for L2 vocabulary acquisition among EFL and ESL learners. As Rodgers' (2013) findings revealed, 
EFL learners generally agree that video captions are beneficial for vocabulary learning, comprehension, and listening capacity. On the other hand, captions and lexical coverage on incidental vocabulary acquisition may not be linked. For example, Rodgers (2013) found that vocabulary learning may be reduced irrespective of whether or not the captions are presented. This may be due to the images contributing to a decrease in incidental vocabulary learning.

According to the findings of this present study, the EFL students revealed positive attitudes towards L1 and L2 video captions. The results of this study are in accordance with the finding in a study by Gasigijtamrong (2013) that Thai EFL learners recalled L2 words after using multimedia vocabulary annotations in both Thai and English. Gasigijtamrong (2013) asserts that multimedia annotations are useful for learning new words and their meaning without having to ask for support from teachers, classmates, or a dictionary. In addition, Aloquili (2014) reported on the benefits of L1 and L2 subtitled videos for learning vocabulary. Aloquali (2014) found that when attempting to master new vocabulary, learners perceived the role of L1 translation as significant. For Aloquali (2014), translation is viewed as an important vocabulary learning strategy, especially for beginners with a low proficiency level, as their L2 vocabulary knowledge is not sufficient to help them infer the meaning of a word from its context. Importantly, Aloquali (2014) clarified that learners may gain benefits from the cognitive effects of interlingual subtitles that may assist them to relaxed and feel less anxious during their viewing experience, particularly due to their lack of grammatical capacity.

\subsection{Image Capacities for Facilitating L2 Word Recognition}

The results of this study revealed that images presented in the video can enhance the EFL learners' understanding of L2 vocabulary meaning. This result is consistent with Mayer's (2005) concept of image processing. According to Mayer (2005), learners engage with the pictures in multimedia messages to create images in their working memory. From this process, learners ultimately gain knowledge in their long-term memory as their prior knowledge is used to support new learning (Mayer, 2005, pp. 40-41). In addition, this finding supports Wang's (2012) finding that video images assist EFL adult learners to memorize L2 vocabulary easily. As Wang (2012) claims, the meanings and functions of vocabulary are recognizable after learners watch and hear the target vocabulary a few times. Similarly, Zarei and Gilanian's (2013) found that L2 learners are generally satisfied with using multimedia while learning L2 vocabulary. The authors suggest that this is because multimedia changes the instructional environment into a relaxing and interesting setting for L2 learning. Thus, Zarei and Gilanian (2013) recommend the use of visual images in language classrooms to create a more pleasurable instructional environment for L2 vocabulary development by learners.

\section{Conclusion}

This study revealed the effects of English vocabulary video on the EFL learners' L2 vocabulary learning. The two main findings are that Thai EFL students gained vocabulary knowledge after viewing the English vocabulary video that included captions, images, and audios related to the target language. The EFL students preferred learning unfamiliar vocabulary via video which contained both L1 and L2 captions, interesting and related images, and proper volume audios. The results from the interviews also uncovered that the obstacles the EFL learners encounter when learning L2 vocabulary via video may be due to modality obstacles around viewing the video: (a) audio obstacles - background music is too loud; (b) image obstacles - irrelevant images, uninteresting images, images presented to quickly; and (c) caption obstacles - long L1 and L2 captions, too fast captions, too small captions, and too formal captions.

Theoretically, the findings of this study support the CTML principle related to multiple representations that "it is better to present an explanation in words and pictures than solely in words" (Mayer, 2005, p. 2). The findings of this study revealed that vocabulary knowledge was acquired through the use of videos as multimedia that allowed the learners to access both visual and audio L2 vocabulary information. Learning L2 vocabulary through multimedia enables L2 learners to receive information about unfamiliar target language vocabulary through audio and visual modes. When L2 learners hear English pronunciations and then view images and L1 and L2 captions in both the L1 and L2 language they can store the visual images in their visual working memory. Consequently, EFL learners can achieve L2 vocabulary learning after viewing English vocabulary videos contributing to early stage L2 vocabulary acquisition.

Pedagogically, the findings of this study may provide implications for EFL teachers and educational multimedia material developers. EFL teachers can enhance learner L2 vocabulary acquisition and L2 learning development by promoting vocabulary knowledge using multimedia materials such as video clips, mobile applications, films, music, animations, and graphics. In EFL classrooms, L1 and L2 captions, related images, and proper volume of audio backgrounds may enhance the L2 learners' interests and motivation in learning unfamiliar English 
vocabulary. In addition, educational material developers may develop multimedia for EFL classrooms to design multimedia materials by considering proper and effective captions, images, and audios to engage L2 learners. Therefore, to assist EFL learners to gain L2 vocabulary acquisition, appropriate multimedia modes of L2 vocabulary learning should be considered in EFL classrooms.

In conclusion, this study provides implications for further research on L2 vocabulary acquisition. Limitations of this study include less research focuses on the captions, images, and audios in the video with the L2 vocabulary meaning, the learners' interest and motivation to learn L2 vocabulary, and EFL learners' opportunities to access English language videos outside EFL classrooms. Thus, future research on L2 vocabulary learning in this digital age should incorporate multimedia technologies such as mobile devices because the mobile phone for instance is a multimedia technology that L2 learners can use to communicate, learn, and socialize (Gurkan, 2018, p. 290). Mobile-Assisted Language Learning (MALL) should be considered for L2 vocabulary learning since the mobile application is effective, motivating, and useful for language learners (Gurkan, 2018). MALL may provide more opportunities for L2 learners to access language outside of the classroom. Importantly, reliable, high quality audio and video delivery to user-friendly mobile devices can provide valuable and enjoyable language input to learners (Khazaie, 2011, p. 174).

\section{Acknowledgments}

I would like to thank the School of Liberal Arts, University of Phayao (UP), Thailand for providing me funding to conduct this research. I also wish to thank the University for allowing me access to their classrooms to collect data. Lastly, I am grateful to the students who participated in this study.

\section{References}

Alhamami, M. (2014). Vocabulary learning through audios, images, and videos: Linking technologies with memory. CALL-EJ, 17(2), 87-112.

Aloqaili, G. S. (2014). Learning vocabulary from subtitled videos: An investigation into the effectiveness Of using subtitled videos for intentional vocabulary learning in Saudi Arabia with an exploration of learners' perspective (Online). University of Southampton: UK.

Arndt, H. L., \& Woore, R. (2018). Vocabulary learning from watching YouTube videos and reading blog posts. Language Learning \& Technology, 22(3), 124-142. http://hdl.handle.net/10125/44660

Azman, W. A., \& Mei, L. L. (2015). Effect of multimedia principle on vocabulary learning among second language learners. Proceedings of SOCIOINT. 15-2 ${ }^{\text {nd }}$ International Conference on Education, Social Science and Humanities. Istanbul, Turkey.

Boonkongsaen, N., \& Intaraprasert, C. (2014). Use of English vocabulary learning strategies by Thai tertiary-level students in relation to fields of study and language learning experiences. English Language Teaching, 7(5), 59-70. http://doi.org/10.5539/elt.v7n5p59

Cepon, S. (2013). Effective use of the media: Video in the foreign language classroom. Medij Istrz, 83-104.

Durbahn, M. (2019). Incidental vocabulary acquisition form documentary viewing: A study on the role of captions. Arboles Rizomas, 1(1), 75-96. https://doi.org/10.35588/ayr.v1i1.3776

Gasigijtamrong, J. (2013). Effects of multimedia annotations on Thai EFL readers' words and text recall. English Language Teaching, 6(12), 48-57. http://doi.org/10.5539/elt.v6n12p48

Gurkan, S. (2018). The effects of a mobile assisted vocabulary learning application on vocabulary learning. Turkish Online Journal of Qualitative Inquiry (TOJQI), 9(3), 288-311. http://doi.org/10.17569/tojqi.407512

Kabooha, R., \& Elyas, T. (2018). The effects of YouTube in multimedia instruction for vocabulary learning: Perception of EFL students and teachers. English Language Teaching, 11(2), 72-81. http://doi.org/10.5539/elt.v11n2p72

Kanellopoulou, C.; Kermanidis, K.L.; Giannakoulopoulos, A. (2019) The Dual-Coding and Multimedia Learning. Theories: Film Subtitles as a Vocabulary Teaching Tool. Educ. Sci., 9 (210), 1-13. https://doi.org/10.3390/educsci9030210

Khazaie, S., \& Ketabi, S. (2011). Contribution to vocabulary learning via mobiles. English Language Teaching, 4(1), 174-184. https://doi.org/10.5539/elt.v4n1p174

Ko, M. H., \& Goranson, J. (2014). Technology-assisted vocabulary learning and student learning outcomes: A case study. Multimedia-Assisted Language Learning, 17(1), 11-33. https://doi.org/10.15702/mall.2014.17.1.11 
Lin, C., \& Tseng, Y. (2012). Videos and animations for vocabulary learning: A study on difficult words. The Turkish Online Journal of Education Technology, 11(4), 346-355.

Lin, L. F. (2010). English learners' incidental vocabulary acquisition in the video-based CALL program. Asian EFL Journal, 12(4), 1-16.

Lin, L. F. (2011). Gender differences in L2 comprehension and vocabulary learning in the video-based CALL program. Journal of Language Teaching and Research, 2(2), 295-301. https://doi.org/10.4304/jltr.2.2.295-301

Liu, S. H. J., Lan, Y. J., \& Jenkins, J. R. (2014). Technology-enhanced strategy use for second language

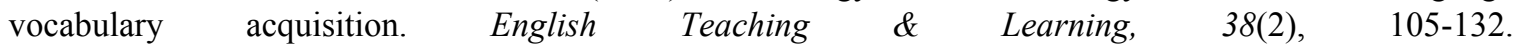
https://doi.org/10.6330/ETL.2014.38.2.04

Maftoon, P., Hamidi, H., \& Sarem, S. N. (2012). The effect of CALL on vocabulary learning: A case of Iranian intermediate EFL learners. Article Intelligence and Neuroscience, 3(4), 2067-3957.

Mayer, R. E. (2005). Cognitive theory of multimedia learning. In R. E. Mayer (Ed.), The Cambridge handbook of multimedia learning, 31-48. Cambridge University Press. https://doi.org/10.1017/CBO9780511816819.004

Mayer, R. E. (Ed.). (2014). The Cambridge handbook of multimedia learning. New York, NY: Cambridge University Press. https://doi.org/10.1017/CBO9781139547369

Mohsen, M. \& Balakumar, M. (2011). A review of multimedia glosses \& their effects on L2 vocabulary acquisition in CALL literature. ReCALL, 23(2), 135-159. https://doi.org/10.1017/S095834401100005X

Nation, I. S. P. (2001). Learning vocabulary in another language. Cambridge, UK: Cambridge University Press. http://doi.org/10.1017/CBO9781139524759

Nation, I. S. P. (2008). Teaching Vocabulary: Strategies and Techniques. Boston: Heinle Cengage Learning. 222 pages. ISBN-13: 978-1-4240-0565-9; ISBN-10: 1-4240-0565-5

Rahimi, M., Allahyari, A. (2019). Effect of multimedia learning combined with strategy-based instruction on vocabulary learning and strategy use. SAGE Open, 9(2). https://doi.org/10.1177/2158244019844081

Ramezanali, N., \& Faez, F. (2019). Vocabulary learning and retention through multimedia glossing. Language Learning \& Technology, 23(2), 105-124. https://doi.org/10125/44685

Ramos, F. D. R. (2015). Incidental vocabulary learning in second language acquisition: A literature review. PROFILE Issues in Teachers' Professional Development, 17(1), 157-166. https://doi.org/10.15446/profile.v17n1.43957

Rasouli, F., \& Jafari, K. (2016). A deeper understanding of L2 vocabulary learning and teaching: A review study. International Journal of Language and Linguistics, 4(1), 40-46. https://doi.org/10.11648/j.ij11.20160401.16

Rodgers, M. P. H. (2013). English Language learning through viewing television: An investigation of comprehension, incidental vocabulary acquisition, lexical coverage, attitudes, and captions (Unpublished doctoral dissertation). Wellington, NZ: Victoria University.

Saengpakdeejit, R. (2014). Awareness of vocabulary learning strategies among EFL students in Khon Kaen University. Theory and practice in language studies, 4(6), 1101-1108. https://doi.org/10.4304/tpls.4.6.1101-1108

Schmitt, N. (1995). A fresh approach to vocabulary: Using a word knowledge framework. RELC Journal, 26(1), 86-94. https://doi.org/10.1177/003368829502600105

Shao, J. (2012). A study of multimedia application-based vocabulary acquisition. English Language Teaching, 5(10), 202-207. http://doi.org/10.5539/elt.v5n10p202

Sok, S. (2014). Deconstructing the concept of 'incidental' L2 vocabulary learning. TESOL \& Applied Linguistics, 14(2), 21-37.

Sydorenko, T. (2010). Modality of input and vocabulary acquisition. Language Learning \& Technology, 4(2), 50-73.

Tabar, H., Khodareza, M. (2012). The effect of using multimedia on vocabulary learning of pre-intermediate and intermediate Iranian EFL learners. Journal of Basic and Applied Scientific Research, 2(12), 12879-12891. 
Vasu, S., \& Dhanavel, S. P. (2015). Understanding the attitude of ESL learners to vocabulary learning. Caliadoscopic, 13(2), 218-226.

Wang, Y. (2012). Learning L2 vocabulary with American TV drama from the learner's perspective. English Language Teaching, 5(8), 217-225. http://doi.org/10.5539/elt.v5n8p217

$\mathrm{Xu}, \mathrm{J}$. (2010). Using multimedia vocabulary annotations in L2 reading and listening activities. CALICO Journal, 27(2), 311-327. https://doi.org/10.11139/cj.27.2.311-327

Zarei, A. A., \& Gilanian, M. (2013). The effect of multimedia modes on L2 vocabulary learning. International Journal of Management and Humanity Science, 2(5), 1011-1020.

\section{Copyrights}

Copyright for this article is retained by the author(s), with first publication rights granted to the journal.

This is an open-access article distributed under the terms and conditions of the Creative Commons Attribution license (http://creativecommons.org/licenses/by/4.0/). 